\title{
Effects of Using Free Sample Medications on the Prescribing Practices of Family Physicians
}

\author{
Barbalee Symm, PhD, RN, Michael Averitt, DO, Samuel N. Forjuoh, MD, DrPH, and \\ Cheryl Preece, $M S, M P H$
}

Introduction: We determined whether family physicians (FPs) who distribute free sample medications are more likely to prescribe those medications than physicians who do not.

Methods: We reviewed administrative health plan prescription data of three similar clinics with 23 FPs within a comprehensive health care delivery system. Only clinic $X$ physicians dispensed free sample medications. To determine which prescribed medications to study, the sample medications $\log$ from clinic $X$ was categorized. The 25 sample medications most frequently dispensed by category were selected as study medications. Outcome measures included the number, proportion, cost, and formulary status of study medications prescribed and the average 30-day prescription costs.

Results: Physicians at clinic $\mathrm{X}$ prescribed the largest proportion of prescriptions for study medications, the smallest proportion of preferred name brands among study medications, and had the highest costs for prescriptions of non-listed formulary study medications $(P<.0001)$. The average 30-day prescription costs differed significantly by clinic $(P<.0001)$, with clinic $X$ being the highest. There was a significant association between the number of samples dispensed and the number of prescriptions written for study medications by physicians at clinic X $(P=.006)$.

Conclusions: Our data support the conclusion that FPs who distribute free samples are more likely to prescribe those medications than their counterparts who do not. (J Am Board Fam Med 2006;19: 443-9.)

The escalation of medication costs in the United States is alarming and has been identified as a national crisis issue. ${ }^{1}$ In less than 5 years, medication costs in the United States have doubled, rising from $\$ 75$ billion annually to over $\$ 150$ billion. ${ }^{2,3}$ The medication cost crisis is very complex with many stakeholders, including pharmaceutical companies, third party payers, patients, and physicians.

The pharmaceutical industry spent over $\$ 12$ billion in 1998 to promote its products in the United States. Of this promotional budget, over half was dedicated to supplying physicians with free sample medications for distribution to patients. This ex-

This article was externally peer-reviewed.

Submitted 19 December 2005; revised 4 May 2006; accepted 22 May 2006.

From the Department of Family and Community Medicine, Scott \& White Memorial Hospital and Scott, Sherwood and Brindley Foundation, Texas A\&M University System Health Science Center, College of Medicine, Temple, TX.

Funding: Scott \& White Institutional Research Fund.

Conflict of interest: none declared.

Corresponding author: Samuel N. Forjuoh, MD, DrPH, Department of Family and Community Medicine, Scott \& White Memorial Hospital Santa Fe-Century Square, 1402 West Avenue H, Temple, TX 76504 (E-mail: sforjuoh@swmail.sw.org). pense increased to almost $\$ 15.7$ billion in 2000, with free sample medications once more topping the budget, having increased an average of $12.8 \%$ annually since $1996 .{ }^{4}$ The extent of reaching physicians with this promotional strategy is remarkable, with one recent survey indicating that $92 \%$ of physicians had accepted free sample medications from pharmaceutical representatives. ${ }^{5}$ Despite this, some physicians may not believe they are influenced by drug company strategies. ${ }^{6-8}$

Physicians' attitudes toward the use of free sample medications vary considerably. In the framework of concern for the high cost of medications to patients, physicians may believe that offering free sample medications to patients is a great service, especially for indigent patients. Another benefit rests in the easy availability of medication to immediately begin a course of therapy. There is also the opportunity to use free sample medications to evaluate patient tolerance and adjust dosage before a full prescription would be written for the patient.' In addition, there are countless benefits for pharmaceutical companies. ${ }^{6,10}$

Current research related to free sample medications center on multiple issues such as the possibil- 
ity of misuse by pharmaceutical representatives ${ }^{11}$ and personal use of free sample medications by physicians and their office staff. ${ }^{12}$ Tong and Lien's study ${ }^{11}$ revealed that of 27 pharmaceutical representatives surveyed, only 11 had not taken those sample medications themselves, provided them to friends or relatives, or exchanged them with other pharmaceutical representatives. The more substantial problems, however, relate to physicians' inclination to prescribe the newer and more expensive medications that may be no more effective than well-known and established drug therapies. ${ }^{13}$ Sales of these newer medications have substantially accelerated, suggesting that pharmaceutical promotions including distribution of free sample medications may have contributed to the adoption of these therapies. This is despite the perception among physicians that they pay little or no attention to drug advertising.

In their recent, comprehensive review of the literature, Groves, Sketris, and Tett ${ }^{14}$ identified 23 papers focused, at least partially, on the impact of the distribution of sample medications by physicians. Of these articles, 15 identified the influence on prescribing behavior as a key issue, 9 addressed the resultant drug expenditure as a key issue, four identified the problem of unregulated handling in the delivery and receipt of the sample medications, 3 dealt with self-medication issues, 2 identified problems related to disposal problems, and 2 discussed resale of free sample medications to pharmacies or trading with others. All studies were observational. The authors concluded that although the marketing strategy of distributing free sample medications promotes the trial and introduction of new drugs, it might be contrary to the quality use of medications. The authors pointed out a lack of research focused on the negative aspects of free sample medications and recommended careful policy addressing quality medicine related to the use of sample medications. None of the studies in this meta-analysis demonstrated that physicians who use sample medications are more likely to prescribe those medications than physicians who do not use samples.

The objective of the current study was to assess family physicians' prescribing practices in relation to the distribution of free sample medications. We hypothesized that family physicians who distribute free sample medications are more likely to prescribe those medications than those who do not.

\section{Methods}

Scott \& White is a large complex comprehensive health care delivery system with a 450-bed level one trauma center, an acute care teaching hospital, a $500+$ physician multispecialty clinic, 14 regional clinics, 3 dialysis centers, 2 ambulatory care surgical centers, and a 180,000-member health maintenance organization (Scott \& White Health Plan [SWHP]). This study was reviewed and approved by the Scott \& White Institutional Review Board.

Physician practice regarding the dispensing of free sample medications within all Scott \& White facilities is governed by written policy. That organizational policy requires that any clinic where free sample medications are dispensed must define mechanisms whereby any sample medication dispensed from that clinic could be identified in the event of a recall.

The participating sites were three Scott \& White regional clinics including one clinic (clinic $\mathrm{X}$ ) where sample medications were dispensed. Two clinics that do not dispense free sample medications (clinic $\mathrm{Y}$ and $\mathrm{Z}$ ) but are similar in community population, location, and number of physicians were selected as comparison groups. All other Scott \& White regional clinics are substantially larger, smaller, or located in communities vastly larger or smaller than these 3 clinics. SWHP case mix adjustment data indicates very similar practices among the 3 clinics with over $50 \%$ of visits from SWHP members. The prescribing practices of the individual family physicians were examined as well as the prescribing practice of each clinic, as a whole. Physicians at all three clinics had equal access to formulary education, counter-detailing efforts, and equal incentives to manage drug costs.

In the single clinic (clinic $\mathrm{X}$ ) where samples were dispensed, a sample log was maintained in accordance with Scott \& White policy, where all free sample medications dispensed were recorded. The sample log from 2003 was used to determine which medications were most frequently used. During the study period, 7 reconciliation reports, which compared the inventory of sample medications to the amount of sample medications received and dispensed, indicated that the 2003 sample log was $95 \%$ to $100 \%$ accurate. There is no way to verify the accuracy of the reconciliation reports, and the logs were assumed to be an accurate reflection of the distribution of sample medications during that 


\begin{tabular}{|c|c|c|}
\hline Name Brand Medication & Formulary Status & General Pharmacy Index 4 Category \\
\hline Aciphex & B tier brand & Proton pump inhibitors \\
\hline Actonel & B tier brand-maintenance benefit & Calcium regulators \\
\hline Allegra & B tier brand & Antihistamine-non-sedating \\
\hline Amaryl & B tier brand-maintenance benefit & Sulfonylureas \\
\hline Augmentin & B tier brand & Penicillin combinations \\
\hline Avandia & $\mathrm{C}$ tier non-preferred & Insulin-sensitizing agents \\
\hline Avelox & C tier non-preferred & Fluoroquinolones \\
\hline Clarinex & Not listed & Antihistamine-non-sedating \\
\hline Cozaar & B tier brand-maintenance benefit & Angiotensin II receptor antagonists \\
\hline Detrol La & C tier non-preferred & Urinary antispasmodics \\
\hline Ditropan $\mathrm{Xl}$ & Not listed & Urinary antispasmodics \\
\hline Elidel & Not listed & Immunomodulating agents_-dermatitis \\
\hline Imitrex & B tier brand & Serotonin agonists \\
\hline Lexapro & Unlisted & Selective serotonin reuptake inhibitors \\
\hline Maxalt & B tier brand & Serotonin agonists \\
\hline Nasacort & B tier brand & Nasal steroids \\
\hline Nexium & Not listed & Proton pump inhibitors \\
\hline Oxytrol & Not listed & Urinary antispasmodics \\
\hline Paxil & B tier brand & Selective serotonin reuptake inhibitors \\
\hline Protonix & B tier brand & Proton pump inhibitors \\
\hline Toprol Xl & B tier brand-maintenance benefit & Beta blockers cardioselective \\
\hline Valtrex & C tier non-preferred & Herpes agents \\
\hline Vioxx & $\mathrm{C}$ tier non-preferred & Nonsteroidal anti-inflammatory drugs \\
\hline Wellbutrin & Unlisted (SR is listed) & Miscellaneous antidepressants \\
\hline Zocor & B tier brand-maintenance benefit & HMG CoA reductase inhibitors \\
\hline
\end{tabular}

* Formulary Scott \& White Health Plan (SWHP) preference in descending order: (1) A tier = non-name brand generic; (2) B tier-maintenance benefit = specific name brand with quantity discounts for SWHP pharmacies; (3) B tier = specific name brand; (4) $\mathrm{C}$ tier = non-preferred name brand; (5) unlisted.

period. Data from this log including physician name, medication name, medication strength, and amount of sample medication dispensed were transcribed from the handwritten log into an electronic database where they were depersonalized. The sample medications were classified according to a commercial classification system used by SWHP known as the Medi-Span therapeutic classification system general pharmacy index (GPI). and the top 3 medications dispensed as free samples in each high level group were selected for analysis to assure that a broad array of prescribed medications would be examined. Only one topical medication was selected. The 25 sample medications selected comprised $84 \%$ of the sample medications dispensed during the study period. Table 1 defines the selected medications. Study medications are listed with their GPI category and formulary status.

A cross-sectional design was used with retrospective review of SWHP prescription claims data.
Prescribing data from the SWHP pharmacies for 2003 including clinic name, physician name, medication name, medication strength, number of days' supply prescribed, number of prescriptions, and cost of prescription were copied to a database and depersonalized, then to a statistical package for analysis.

Data analysis included frequencies and descriptive statistics of the study measures. Group differences were assessed using the $\chi^{2}$ test for categorical data and ANOVA for continuous data for significant differences among clinics with Duncan's post hoc tests, if indicated. All prescriptions written by participating physicians for SWHP members during 2003 were classified as either written for a study medication or for a non-study medication and were compared by clinic. All prescriptions written for study medications were classified by formulary status, and the results were analyzed by clinic. Calculating the average 30-day prescription cost for each 
Table 2. Prescriptions for Non-study and Study Medications by Clinic*

\begin{tabular}{lccccr}
\hline & & \multicolumn{2}{c}{ Non-study Medications } & & \multicolumn{2}{c}{ Study Medications } \\
Clinic & Total Prescriptions & No. & $\%$ & & No. \\
\hline X† & 50,849 & 43,750 & 86.0 & 7099 & 14.0 \\
Y & 50,686 & 44,642 & 88.1 & 6044 & 11.9 \\
$Z$ & 42,907 & 37,180 & 86.7 & 5727 & 13.4 \\
Total & 144,442 & 125,572 & 86.9 & 18,870 & 13.1 \\
\hline
\end{tabular}

${ }^{*} P<.0001$ using $\chi^{2}$ test.

† Significantly different from the rest in proportions of prescriptions for study medications.

physician and for each clinic normalized the data. For those physicians in clinic X, Pearson correlation was used to examine the association between the number of prescriptions written for study medications and the number of samples dispensed by physician. In addition to computing Pearson's coefficient of correlation $(r)$ for each physician, a Bonferroni adjusted $P$ statistic was computed for all physicians. All tests were two-sided tests and were considered significant at $P<.05$.

\section{Results}

\section{Sample Medications Distributed}

During calendar year 2003, there were 18,099 sample packets of 78 prescription medications that were recorded in 2771 sample records dispensed by 8 different family physicians in clinic X. This did not include 161 sample records for non-prescription sample medications. The 25 medications selected for this study represented $84 \%$ of the sample records. Clinic $\mathrm{X}$ was the only clinic dispensing samples.

\section{Prescriptions for Study Medications versus Non-study Medications}

The 23 family physicians providing patient care in the 3 study clinics were responsible for 144,442 total prescrip- tions at a cost of $\$ 6,315,673$ to SWHP patients in 2003. Of this, 18,870 (13\%) prescriptions were written for the 25 study medications. There were significant differences among the 3 clinics regarding prescriptions written for non-study medications and study medications (Table 2); clinic X significantly wrote the largest proportion of prescriptions for study medications $\left(\chi^{2}=97.01 ; P<.0001\right)$.

There was a significant association between the number of free sample medications dispensed and the number of prescriptions written for study medications by physicians at clinic $\mathrm{X}$ (Bonferroni adjusted $P=.006$ ). The Pearson's coefficients of correlation were significant for 7 of the 8 physicians, ranging from 0.78 to 0.99 . The coefficient for the eighth physician was $0.62(P=.06)$ (data not shown).

\section{Prescriptions for Study Medications by Formulary Status}

Formulary status for each study medication was identified as a preferred name brand, a non-preferred name brand, or a medicine not included in formulary (unlisted) as demonstrated in Table 3. There were significant differences among the 3 clinics regarding the number of prescriptions written by formulary status, with clinic $\mathrm{X}$ significantly

Table 3. Prescriptions by Formulary Status of Medication and Clinic*

\begin{tabular}{|c|c|c|c|c|c|c|c|}
\hline \multirow[b]{2}{*}{ Clinic } & \multirow[b]{2}{*}{ Total Prescriptions } & \multicolumn{2}{|c|}{$\begin{array}{c}\text { Preferred Name } \\
\text { Brand }\end{array}$} & \multicolumn{2}{|c|}{$\begin{array}{l}\text { Non-preferred } \\
\text { Name Brand }\end{array}$} & \multicolumn{2}{|c|}{$\begin{array}{l}\text { Not Included in } \\
\text { Formulary }\end{array}$} \\
\hline & & No. & $\%$ & No. & $\%$ & No. & $\%$ \\
\hline $\mathrm{X} \dagger$ & 7099 & 6,246 & 88.0 & 529 & 7.5 & 324 & 4.6 \\
\hline $\mathrm{Y}$ & 6044 & 5,359 & 88.7 & 380 & 6.3 & 305 & 5.1 \\
\hline Z & 5727 & 5,056 & 88.3 & 482 & 8.4 & 189 & 3.3 \\
\hline Total & 18,870 & 16,661 & 88.2 & 1,391 & 7.4 & 818 & 4.3 \\
\hline
\end{tabular}

${ }^{*} P<.0001$ using $\chi^{2}$ test.

† Significantly different from the rest in prescriptions for preferred name brand medications. 
Table 4. Average Cost of 30-Day Prescription by Clinic*

\begin{tabular}{lccccc}
\hline Clinic & No. of Physicians & Mean & SD & Min & Max \\
\hline $\mathrm{X} \dagger$ & 8 & $\$ 47.57$ & $\$ 4.32$ & $\$ 41.83$ & $\$ 56.67$ \\
$\mathrm{Y}$ & 8 & $\$ 39.49$ & $\$ 2.49$ & $\$ 34.92$ & $\$ 42.04$ \\
$\mathrm{Z}$ & 7 & $\$ 41.48$ & $\$ 1.94$ & $\$ 38.17$ & $\$ 43.97$ \\
\hline
\end{tabular}

${ }^{*} P<.0001$ using ANOVA.

$\dagger$ Significantly different from the rest in average cost of 30-day prescription.

prescribing the lowest proportion of preferred name brand medications $\left(\chi^{2}=40.41 ; P<.0001\right)$.

\section{Cost of Written Prescriptions}

The average cost of a 30-day prescription also differed significantly by clinic $(F[3,23]=14.33, P<$ .0001). Duncan's post hoc test revealed that clinic $\mathrm{X}$ physicians were significantly higher in the average cost per 30-day prescription than those in clinic $\mathrm{Y}$ or clinic $\mathrm{Z}$, with those in clinics $\mathrm{Y}$ and $\mathrm{Z}$ being similar (Table 4). Of the total cost of all prescriptions written for patients $(\$ 6,316,673)$, prescriptions written for the 25 study medications amounted to $\$ 1,894,485$ or $30 \%$. Further analysis by total cost showed significant differences among the clinics, with clinic $\mathrm{X}$ being responsible for the highest total costs for unlisted formulary medications (Table 5).

\section{Discussion}

The day-to-day practice of medicine is very complex. Physicians are sensitive to the rapidly escalating cost of health care and are interested in helping patients cope with that high cost. Physicians who dispense free sample medications are convinced they are helping patients, and do not necessarily believe that their prescribing behavior is influenced by pharmaceutical companies. ${ }^{7,8}$ Some organizations, including ours, are taking steps to dampen the effects of pharmaceutical company strategies. These might include special directives to control when and how often drug representatives can see physicians as well as policies related to tight control of free sample medications, or whether or not sample medication distribution should be allowed. Special presentations related to medication expense and the organizational effect have been made to all family physicians. On occasion, specifically targeted medication prescriptions have been changed as a result of a family medicine departmental effort.

Although some physicians may believe their prescribing practices are not influenced by the use of free sample medications, ${ }^{7,8}$ our data suggest otherwise about our family physicians. In the practice of a physician whose prescribing was influenced by the use of sample medications, one might possibly expect to see a higher than usual cost of prescriptions ordered for patients, since pharmaceutical companies typically try to promote their newer, expensive medications. If a physician is influenced by the use of free sample medications, one might also expect to see comparatively more prescriptions written for medications that the physician dispensed as sample medications. Scott \& White does not mandate prescriptions only for formulary medications. Under these circumstances, if free sample medications influence physician prescribing, one might also expect to see fewer formulary-preferred

Table 5. Total Prescription Costs of Study Medications by Formulary Status and Clinic*

\begin{tabular}{|c|c|c|c|c|c|c|c|}
\hline \multirow[b]{2}{*}{ Clinic } & \multirow[b]{2}{*}{ Total Prescriptions } & \multicolumn{2}{|c|}{ Preferred Name Brand } & \multicolumn{2}{|c|}{$\begin{array}{c}\text { Non-preferred Name } \\
\text { Brand }\end{array}$} & \multicolumn{2}{|c|}{$\begin{array}{l}\text { Not Included in } \\
\text { Formulary }\end{array}$} \\
\hline & & Costs & $\%$ & Costs & $\%$ & Costs & $\%$ \\
\hline $\mathrm{X} \dagger$ & $\$ 711,482$ & $\$ 621,589$ & 87.4 & $\$ 54,547$ & 7.7 & $\$ 35,345$ & 5.0 \\
\hline $\mathrm{Y}$ & $\$ 646,885$ & $\$ 584,272$ & 90.3 & $\$ 34,110$ & 5.3 & $\$ 28,504$ & 4.4 \\
\hline Z & $\$ 536,118$ & $\$ 471,848$ & 88.0 & $\$ 44,724$ & 8.3 & $\$ 19,546$ & 3.7 \\
\hline Total & $\$ 1,894,485$ & $\$ 1,677,709$ & 88.5 & $\$ 133,381$ & 7.0 & $\$ 83,395$ & 4.4 \\
\hline
\end{tabular}

${ }^{*} P<.0001$ using $\chi^{2}$ test.

† Significantly different from the rest in total costs for unlisted formulary medications. 
medications prescribed than that of a physician not influenced by free sample medications. Furthermore, one might expect to see more cost for nonformulary medications prescribed by a physician influenced by the use of free sample medications, because sample medications distributed by pharmaceutical companies are frequently the newer, more expensive medications, and because it takes some time for a medication to become formulary-approved. Although some results are weak because of the large numbers used in the analyses, our data do suggest to us that our family physicians' prescribing practices are influenced by the use of free sample medications.

The implications of our conclusions are worthy of consideration, both for physicians and for consumers. For physicians, the knowledge that free sample medications may influence their prescribing behavior independently from clinical judgment must be included in the ethical debate over whether to accept such sample medications. ${ }^{15}$ Although there may be some benefits in using free sample medications, for example as starter dosages and to complete courses of treatment, ${ }^{6,16}$ there are also notable unseen and not easily measured costs to patients. For consumers, this is an excellent fulfillment of often quoted maxim "there is no free lunch." Consumers should also be aware that advertising is effective, that free sample medications are not always in their best interest and that sample medications may not be cost-effective for them. A free sample medication today may seem to reduce the cost of care for the moment but may result in a long-term prescription much more expensive than is perhaps necessary.

We recognize the results of this study are not necessarily generalizable to others and that confounding variables exist. We did not examine clinical outcomes or the quality of care. Although we have case-mix adjustment data that indicates very similar practices among the clinics we studied, there may still have been differences that we overlooked or were unable to measure. We also assumed that care delivered to all patients is the same, whether or not patients were SWHP members. The community in which clinic $\mathrm{X}$ is located has a larger minority population that clinic $\mathrm{Y}$ or clinic $\mathrm{Z}$, but it is not known whether this variation exists in the patient population of these clinics or how any difference might affect the outcomes measured. The average age of the patient population was 43.6 years in clinic $\mathrm{X}$ but was 50.9 years in clinic $\mathrm{Z}$. How this difference might have affected the measured outcomes is also unknown, although one might expect a higher prescription need in an older population. Very large numbers used in $\chi^{2}$ analysis are known to identify the smallest of variability.

Scott \& White physicians see patients other than their own. Any prescription signed by the physician for a SWHP member was credited to that physician's pharmacy record. Although it is believed that the physician would prescribe the same medications for their own patients as with other physician's patients under the same circumstances, that remains unknown. Moreover, patient panels may have differed more than is believed due to critical comorbidities. It is not known how this might have affected the data sets or the analyses.

As another potential confounder, it may also be that the practices of the physicians within the groups are similar to each other and not similar to others in different areas of practice, dealing with the same kinds of patients. Although this information is not known, we do know that all physicians were salaried and did not have any other financial incentives to prescribe medications in one way or another.

It is of interest to note the significant association we found between the number of samples distributed and the number of prescriptions written for study medications among 7 of 8 physicians in clinic $\mathrm{X}$. This may be the strongest evidence presented. As a side note, the lone physician whose numbers were not significantly correlated is in the medical leadership role of clinic $\mathrm{X}$ and assisted in presenting counter-detailing drug information to the medical staff of clinic $X$.

Although the study has substantial limitations, to our knowledge, this is the first study to directly examine the relationship between the use of free sample medications and actual prescriptions written by specific physicians and clinics. Several observations from our findings are relevant. Health care costs are an important national issue, and efforts must be generated from many quarters to assist in bringing down the escalating costs. The cost of prescription medications is an important contributor to those costs and is as current as today's newspaper. A great deal of work is required to educate physicians about the effects of distributing free sample medications. As a body of evidence continues to accumulate, studies such as this can 
help illustrate the consequences of accepting and dispensing free sample medications to patients. Physicians experience pressures from many different directions. This includes pressure from patients who ask for free sample medications. It is incumbent on physicians to analyze honestly and critically data that describe the impact of free sample medications on prescribing practices. More research in this arena will be helpful to demonstrate both the direct and indirect effects of using free sample medications. Responsible researchers in health care must do what pharmaceutical companies have done for many years-study those things that impact physicians' prescribing behaviors, and then publish the results to inform policy changes.

Author contributions were as follows: study concept and design (BS, MA, SNF, CP); acquisition of data (BS, SNF, MA, CP); analysis and interpretation of data (SNF, BS, MA, CP); drafting of manuscript (BS, SNF); critical revision of manuscript for important intellectual content (BS, SNF, MA, CP); statistical expertise (SNF, CP); obtained funding (BS, SNF); and study supervision (BS, SNF).

\section{References}

1. California Healthcare Institute. Another drug cost crisis looms [article on the Internet]. 2003 Sept [cited 2004 Mar 8]. Available from: http://chi.org/home/ article.php? pid $=589$.

2. IMS Health. World drug purchases-retail pharmacies, IMS Health-drug monitor: 12 months to February 2000 [document on Internet]. 2000 [cited 2004 Mar 8]. Available from: http://ww0.ne.imshealth. com/public/structure/attachment/1\%2C2823\% 2C250\%2C00.pdf.

3. IMS Health. Key country drug purchases-retail pharmacies, IMS Health-retail drug monitor: 12 months to May 2003 [document on Internet]. 2003 [cited 2004 Mar 8]. Available from: http://www. w.open.imshealth.com/download/may2003.pdf.

4. Ma J, Stafford RS, Cockbum IM, Findelstein SN. A statistical analysis of the magnitude and composition of drug promotion in the United States in 1998. Clin Ther 2003;25:1503-18.

5. Henry J. Kaiser Family Foundation. National survey of physicians, part II: doctors and prescription drugs [document on the Internet]. 2002. [cited 2004 Sept]. Available from: http://www.kff.org/rxdrugs/loader. cfm? url=/commonspot/security/getfile.cfm \& PageID $=13965$.

6. Westfall JM. Physicians. Pharmaceutical representatives, and patients: who really benefits? J Fam Pract 2000;49:817-9.

7. Wazana A. Physicians and the pharmaceutical industry: is a gift ever just a gift? JAMA 2000;283:373-80.

8. Guldal D, Semin S. The influences of drug companies' advertising programs on physicians. Int J Health Serv 2000;30:585-95.

9. Chew LD, O'Young TS, Hazlet TK, Bradley KA, Lessler DS. A physician survey of the effect of drug sample availability on physicians' behavior. J Gen Intern Med 2000;15:478-84.

10. Elling ME, Fogle HJ, McKhann CS, Simon C. Making more of pharms's sales force [article on the Internet]. The McKinsey Quarterly 2002 Jun [cited 2004 Sept 4];102(6). Available from: http://www. mckinseyquarterly.com/.

11. Tong KL, Lien CY. Do pharmaceutical representatives misuse their drug samples? Can Fam Physician 1995;41:1363-6.

12. Westfall JM, McCabe J, Nicholas RA. Personal use of drug samples by physicians and office staff. JAMA 1997;278:141-143.

13. Wang TJ, Ausiello JC, and Stafford RS. Trends in antihypertensive drug advertising. Circulation 2003; 99:2055-7.

14. Groves KE, Sketris I, Tett SE. Prescription drug samples-does this marketing strategy counteract policies for quality use of medicines? J Clin Pharm Ther 2003;28:90-109.

15. Brett AS, Burr W, Moloo J. Are gifts from pharmaceutical companies ethically problematic? A survey of physicians. Arch Intern Med 2003;163:2213-8.

16. Backer EL, Lebsack JA, Van Tonder RJ, Crabtree $\mathrm{BF}$. The value of pharmaceutical representative visits and medication samples in community-based family practices. J Fam Pract 2000;49:811-6. 